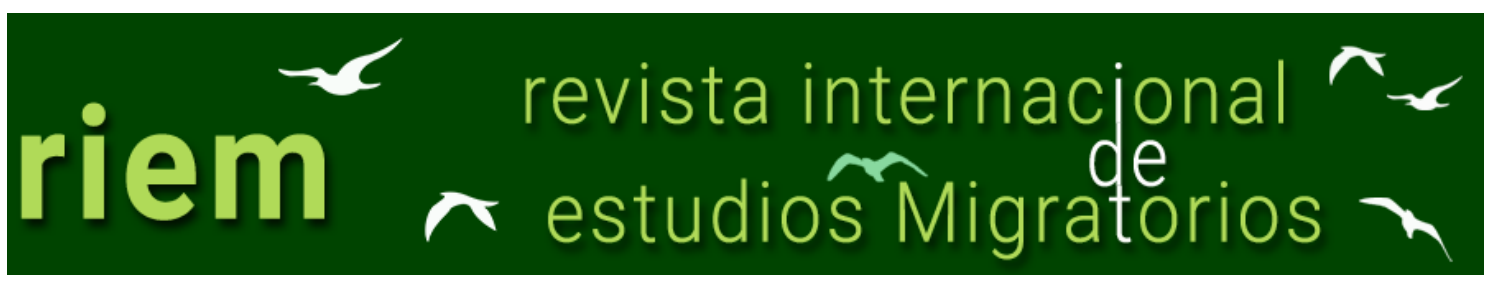

ISSN: 2173-1950

\title{
Migración venezolana reciente en la República Argentina: redes sociales e inserción laboral en Santa Rosa-Toay (La Pampa)
}

María Dolores Linares ${ }^{1}$

Resumen: La República Bolivariana de Venezuela ha experimentado en la última década un cambio rotundo en su patrón migratorio, pasando de ser un país receptor de inmigrantes a un emisor masivo hacia destinos diversos. La República Argentina ha participado en la recepción de este flujo migratorio y se calcula que más de 120.000 migrantes venezolanos han arribado en los últimos tres años (DNM, Radicaciones 2016, 2017 y 2018). El objetivo de este artículo es describir y analizar las trayectorias laborales y las redes sociales de los y las migrantes recientes (2010-2019) en las ciudades de Santa Rosa y Toay, Provincia de la Pampa. Desde la perspectiva teórica de las redes sociales migratorias y a partir de un abordaje cualitativo basado en la realización de entrevistas en profundidad a migrantes venezolanos/as, se analizan las variables relacionadas con las trayectorias laborales y la utilización/constitución de redes sociales migratorias. Se discute las experiencias y percepciones sobre el quiebre en la trayectoria laboral, la informalidad y precariedad laboral y la formación y utilización tanto de redes migratorias virtuales como de aquellas basadas en apoyos personales.

Palabras Clave: redes sociales migratorias, trayectorias laborales, formación, migrantes venezolanos, Argentina.

1 Investigadora, IESHOLP - CONICET, Universidad Nacional de La Pampa, Santa Rosa, Argentina. Dirección postal: Av. 13 de Caballería Oeste 1786, CP: 6303, Toay, La Pampa. Argentina. linares.dolores@gmail.com 


\title{
Recent Venezuelan migration in Argentina: social networks and labour insertion in Santa Rosa-Toay (La Pampa)
}

\begin{abstract}
The Bolivarian Republic of Venezuela has undergone a major change in its migratory pattern in the last decade, going from being a receiving country of immigrants to a country of massive emigration towards different destinations. The Argentine Republic has participated in the reception of this migratory flow: more than 120,000 Venezuelan migrants have arrived in the last three years (DNM, Radicaciones 2016, 2017 and 2018). The aim of this article is to describe and analyze the labour trajectories and social networks of recent Venezuelan migrants (2010-2019) in the cities of Santa Rosa and Toay, Province of La Pampa. From the theoretical perspective of migratory social networks and from a qualitative approach based on in-depth interviews, we will discover and analyze the variables related to labour trajectories and the use / constitution of migratory social networks. Labour trajectory rupture experiences and perceptions, informality and job insecurity, and the formation and use of both virtual migratory networks and those based on personal support are discussed.
\end{abstract}

Keywords: migratory social networks, labour trajectories, eductational training, Venezuelan migration, Argentina. 


\section{Introducción}

La República Bolivariana de Venezuela ha experimentado, en las últimas décadas, un cambio de patrón migratorio con respecto a su tradicional rol como país receptor prevaleciente hasta los años 80 del siglo pasado (Martínez Pizarro y Orrego Rivera, 2016). Desde entonces, pero particularmente a partir del nuevo milenio, las sucesivas crisis económicas y la incertidumbre política y social lo han convertido en un país netamente emisor de migrantes (De La Vega, 2005). Según el Alto Comisionado de Naciones Unidas para los Refugiados, mientras en el año 2005 había 437.280 venezolanos y venezolanas fuera de su país, en el 2019 (al cierre de esta investigación) esta cifra ascendería a más de cuatro millones (ACNUR, 2019; Pacecca, 2019). Esta transformación del patrón migratorio no se evidencia solo en su masividad sino en la diversificación de los principales destinos migratorios, que ya no se circunscriben a Estados Unidos, España o Francia sino también a países latinoamericanos (Koechlin et al., 2018).

En ese contexto, la República Argentina ha participado en la recepción de este flujo migratorio: de más de 12.00o venezolanos residiendo en Argentina en 2015, para el año 2018 se calculaba que se habían alcanzado los 130.000 según las estadísticas de la DNM (DNM Radicaciones 2011-2015, 2016, 2017 y 2018) o 159.526 según el sitio web del ACNUR en el año 2019. La Provincia de La Pampa, aunque se destaca por la emigración interna de su población como constante estructural, en la última década presenta una progresiva recepción de migrantes internacionales (Linares, 2016), entre los cuales se destacan los venezolanos por su crecimiento exponencial, es decir, similar al registrado a nivel nacional.

El objetivo de este artículo es indicar algunas características de la migración venezolana hacia La Pampa entre los años 2010 y 2019, centrando el análisis en las trayectorias laborales y en las redes sociales que la habilitaron. Desde la perspectiva teórica de las redes sociales migratorias nos preguntamos: ¿los migrantes venezolanos utilizaron/constituyeron redes sociales migratorias? ¿Qué incidencia tuvieron estas redes al momento de emprender la trayectoria hacia la Argentina y a La Pampa? Y ¿cómo influyeron en la inserción laboral en el país de destino? La metodología utilizada para esta investigación se basó en el relevamiento de bibliografía especializada en la emigración venezolana, de fuentes estadísticas argentinas (CONARE, radicaciones DNM), e internacionales (ACNUR, ONU). Por otro lado, se buscó la generación de fuentes primarias a partir de un abordaje cualitativo basado en la realización de 
entrevistas en profundidad a migrantes venezolanos en Santa Rosa-Toay2 (ciudad capital de la Provincia de La Pampa y su ciudad satélite) para conformar una muestra del universo estudiado, a partir de la técnica de bola de nieve, que se explicará más adelante.

Con el fin de ordenar nuestra exposición, dedicaremos un primer apartado a la descripción de las líneas teóricas que han guiado nuestra investigación y la definición de los conceptos principales. Luego se detalla la estrategia metodológica utilizada en el trabajo de campo. En tercer lugar, describiremos brevemente los cambios en el patrón migratorio de Venezuela y caracterizaremos los flujos migratorios recientes hacia la Argentina y a La Pampa. Por último, a partir de la sistematización de las entrevistas realizadas, indicaremos los primeros resultados de esta investigación en función de dos ejes: la reconstrucción de las trayectorias laborales y la generación/utilización de redes sociales migratorias por parte de los y las migrantes venezolanas en Santa Rosa-Toay (La Pampa).

\section{Migración venezolana reciente en Argentina desde la perspectiva teórica de las redes sociales migratorias}

Entendemos que el dinamismo, el carácter poliforme y las variaciones en la perdurabilidad de la movilidad humana internacional dificultan la admisión de una teoría general explicativa de las migraciones internacionales (Arango, 2003). Esto no impidió sin embargo la proliferación de modelos de análisis que, con mayor énfasis en cuestiones estructurales (macro) o en las decisiones individuales (micro), se propusieron comprender y explicar no sólo como comienzan los flujos migratorios sino cómo y porqué se perpetúan3. En las últimas décadas, de la mano de diseños metodológicos cualitativos, estas visiones generalistas fueron revisadas para dar cuenta de los diferentes niveles implicados en la migración internacional entendida como hecho social total (Colectivo OIE, 1996: 21; Sayad, 2010). La perspectiva cualitativa propone poner el foco en los y las migrantes, lo que no significa, como establece Revel (2015), oponer un "arriba" sobre un "abajo" sino reconocer -y utilizar como herramienta heurística- que "una realidad social no es la misma según el nivel de análisis o [...] la escala de observación en la que decidamos ubicarnos" (Revel 2015: 15).

\footnotetext{
${ }^{2}$ Se ha tomado por el momento como unidad de análisis el aglomerado urbano que incluye las ciudades de Santa Rosa (Departamento Capital) y Toay (Departamento Toay) porque, aunque pertenece a una jurisdicción departamental diferente, Toay es la ciudad satélite más importante del Gran Santa Rosa dado su cercanía geográfica y su relevancia demográfica.

3 Algunos de estos modelos pueden ser el modelo neoclásico económico y microecónomico, el de la acumulación causal, el del sistema mundo, el institucional o el de los sistemas migratorios (Massey et al., 1993).
} 
Estos tipos de abordajes, como por ejemplo el de la interseccionalidad, no solo han aportado al estudio de las migraciones internacionales dando voz a los y las protagonistas invisibilizadas, sino que han discutido las generalizaciones realizadas en torno a las trayectorias a partir de la reflexión sobre sus posicionalidades múltiples (Guzmán Ordaz, 2009; Magliano, 2015; Viveros Vigoya, 2016).

En relación con estos abordajes cualitativos, para la realización de este trabajo adoptamos la perspectiva de las redes sociales migratorias, que no toma a las decisiones individuales de los y las migrantes como escindidas de las condiciones -y condicionantes- externas, sino como participantes de una realidad social mucho más compleja. Este enfoque, enmarcado dentro de una perspectiva histórica- estructural, ayudaría a comprender la migración como un hecho social (Ramella, 1995), explicando la perpetuación de los flujos migratorios a partir de las facilidades para lograr una trayectoria exitosa gracias a la existencia de una red social. Ésta se formaría mediante al flujo incial y luego se expandirá a diferentes miembros de la comunidad en el país de origen, hasta independizarse de las causas originales del primer flujo. La expansión de la red podrá dar lugar a un momento de masividad de arribos para después estabilizarse y, eventualmente, decrecer. Las redes pueden desalentarse con políticas públicas restrictivas o fomentarse a partir de medidas como la reunificación familiar (Arango, 2003; Massey et al., 1993; Pedone, 2010).

Siguiendo a Pedone, las redes sociales migratorias son estructuras de carácter transnacional que involucran a todas aquellas personas e instituciones vinculadas al proceso migratorio: políticas públicas (en país de origen y de destino), migrantes, empleadores, informantes, asociaciones culturales, políticas, sociales y religiosas, etcétera (Pedone, 2010). Los y las sujetos migrantes y sus grupos familiares son entendidos como agentes productores/as y reproductores/as de lazos, relaciones e información necesaria para la movilidad espacial. Las relaciones directas e indirectas tejidas en torno a la red -definidas por parentesco, amistad, afinidad o relaciones clientelares-permiten el acceso a información, contactos para la inserción laboral, alojamiento en el lugar de destino; elementos que coadyuvarán en la inserción dentro de la sociedad de destino y a la reproducción de los flujos migratorios (Garduño, 2003). En general, las redes se caracterizan por ser mixtas, es decir, están compuestas por connacionales de las personas migrantes, así como de personas nacidas en el país de destino (Bastia, 2007; Camacho, 2010). Pedone advierte que el análisis de la red social permite observar las relaciones de poder construidas en su interior a través del entramado de relaciones verticales $\mathrm{u}$ horizontales (Pedone, 2010). Las relaciones horizontales se caracterizan por la solidaridad, la cooperación y la ayuda, y se desarrollan generalmente entre parientes y amigos. Por su parte, las relaciones 
verticales se estructuran a partir de alguna relación de poder asimétrico, entre paisanos o nacionales del país de destino, vinculada a la obtención de empleo o vivienda, por ejemplo.

El papel que juegan los y las actoras en las redes responderá, en cada caso, a la posición social que ocupan en ese momento. Siguiendo el planteo del Colectivo OIE, es fundamental ubicar las "claves de la posición social de los sujetos (género, clase, etnia, raza, etc.)" (Colectivo OIE, 1996: 22; Pedone, 2010) dentro de una red para comprender sus estrategias y trayectorias migratorias. La perspectiva de la interseccionalidad nos permite pensar las diversas categorías diferenciales que entran en juego en una relación, como las de género, nacionalidad, etnia, que generarán diferentes grados de exclusión o desigualdad según su posicionamiento (Guzmán Ordaz, 2009; Magliano, 2015; Viveros Vigoya, 2016). Como indica Guzmán Ordaz (2009), las experiencias de los y las migrantes no son homogéneas (aunque pertenezcan a un mismo colectivo) y sus relaciones pueden mostrar la intersección o interacción de diferentes categorías sociales que tendrán un efecto único y no aditivo.

Cuando hacemos referencia a las trayectorias migratorias nos referimos a las trayectorias de vida, que comprenden procesos espaciales integrados a la vida social y a la historia de las y los sujetos. Dentro de estos procesos encontramos las trayectorias laborales que, en el caso de los y las migrantes, están constituidas por la experiencia laboral en el lugar de origen y por el tipo de inserción en el mercado de trabajo en el país de destino. La inserción laboral de los y las migrantes venezolanas recientes en la Ciudad Autónoma de Buenos Aires ha sido analizada por Pedone y Mallimaci (2019), Pedone et al. (2019) y Pacecca y Liguori (2019). Estas autoras coinciden en que se caracteriza por la informalidad, la precariedad laboral y un proceso de desclasamiento social producido, entre otras cosas, por el desfase entre la capacitación profesional y laboral en el país de origen y la inserción laboral en destino.

\section{Método}

Se realizaron quince entrevistas a mujeres y hombres provenientes de la República Bolivariana de Venezuela, entre diciembre de 2017 y agosto de 2019 en las ciudades de Santa Rosa y Toay, que fueron gradabas digitalmente. Las entrevistas en profundidad fueron diseñadas mediante el método biográfico para rastrear, a través de las historias de vida, las trayectorias personales y grupales que vinculan no sólo espacios -lugares de origen y de destino- sino también proyectos económicos, familiares, deseos y angustias. Este enfoque permite acercarse a la subjetividad de la persona (Mezzadra, 
2005) ${ }^{4}$ a la luz de su visión particular en la que se refleja, asimismo, una época atravesada por normas y valores compartidos por la sociedad de la que forma -o desea formar- parte.

Siguiendo las normas éticas de protección de la identidad y anonimato, nos referimos a los y las entrevistadas como E1, E2 y así sucesivamente. En la Tabla 1 se presenta un perfil detallado de cada migrante. Las entrevistas en profundidad se basaron en un cuestionario de tres preguntas abiertas que respondían a tres módulos destinados a operacionalizar los diferentes aspectos de la migración hacia La Pampa: 1Módulo residencial, 2- Módulo de las redes sociales y 3- Módulo de la trayectoria laboral. Dentro de cada una de las preguntas abiertas se buscaba información sobre seis variables, sumando dieciocho en total. En esta oportunidad, en virtud de las categorías que queremos analizar, hemos sistematizado la información resultante de las entrevistas en función de las siguientes variables: contactos facilitadores, formación, experiencia laboral en el país de origen, primera inserción laboral en el país de destino, experiencias laborales, formas de contratación y discriminación en el ambiente laboral. Antes de exponer los resultados del análsis de estas variables, se realizará una breve caracterización de la migración venezolana en Argentina y en La Pampa.

\section{Cambio en el patrón migratorio venezolano: crisis y olas migratorias masivas. La Argentina como destino}

Con el fin de contextualizar la migración venezolana reciente en Argentina, realizaremos una descripción del cambio de patrón migratorio de Venezuela, indicando las características de las olas migratorias que predominaron en cada período. En primer lugar, varios autores coinciden en la ausencia de una "cultura de la emigración" en Venezuela, por haber sido durante décadas un país receptor y no emisor de migrantes (Castillo Crasto y Reguant Álvarez, 2017). De la Vega (2005) establece que Venezuela participó de las corrientes inmigratorias transoceánicas que caracterizaron a otros países de América Latina entre fines del siglo XIX y comienzos del siglo XX. Sin embargo, lejos de experimentar un freno a partir de los años treinta, la incipiente actividad petrolera fomentó la llegada de inmigrantes desde fines de los años veinte y no se detuvo sino hasta 1983.

\footnotetext{
$4 \mathrm{El}$ autor propone centrarse en la subjetividad migrante para explorar la "riqueza" de la que son portadores y su capacidad de agencia. Tomar como eje la experiencia del sujeto migrante "no equivale a borrar las causas «objetivas» del origen de la migración, tampoco significa olvidar el modo en que su condición está profundamente caracterizada por circunstancias de privación material y simbólica" (Mezzadra, 2005: 46).
} 
Tabla 1. Perfiles de los migrantes entrevistados

\begin{tabular}{|c|c|c|c|c|c|c|c|}
\hline $\mathbf{N}^{\mathbf{o}}$ & Edad & Género & Procedencia & $\begin{array}{c}\text { Año } \\
\text { llegada } \\
\text { a Arg. }\end{array}$ & $\begin{array}{l}\text { Trabaja } \\
\text { en Arg. }\end{array}$ & $\begin{array}{l}\text { Nivel de } \\
\text { estudios }\end{array}$ & Fecha \\
\hline E1 & 36 & $\mathrm{M}$ & Caracas & 2010 & $\begin{array}{c}\text { Sí } \\
\text { (negocio } \\
\text { propio) }\end{array}$ & Universidad & $\begin{array}{l}\text { Dic. } \\
2017\end{array}$ \\
\hline E2 & 43 & $\mathrm{~F}$ & Caracas & 2012 & $\begin{array}{c}\text { Sí } \\
\text { (negocio } \\
\text { propio) }\end{array}$ & Universidad & $\begin{array}{l}\text { Mar. } \\
2018\end{array}$ \\
\hline E3 & $30 / 40$ & $\mathrm{~F}$ & Caracas & 2017 & $\begin{array}{c}\text { Sí } \\
\text { (secretaria) }\end{array}$ & Universidad & $\begin{array}{l}\text { Abril } \\
2018 \\
\end{array}$ \\
\hline E4 & $30 / 40$ & $\mathrm{~F}$ & $\begin{array}{c}\text { Anaco (Estado } \\
\text { Anzoátegui) }\end{array}$ & 2017 & $\begin{array}{c}\text { Sí } \\
\text { (gastronomía) }\end{array}$ & $\begin{array}{l}\text { Secundario } \\
\text { Universidad } \\
\text { incompleta }\end{array}$ & $\begin{array}{c}\text { Mayo } \\
2018\end{array}$ \\
\hline E5 & $30 / 40$ & $\mathrm{~F}$ & $\begin{array}{c}\text { Anaco (Estado } \\
\text { Anzoátegui) }\end{array}$ & 2017 & $\begin{array}{c}\text { No } \\
\text { (busca) }\end{array}$ & Universidad & Junio 2018 \\
\hline E6 & $30 / 40$ & $\mathrm{M}$ & $\begin{array}{c}\text { Caracas/Los } \\
\text { Teques } \\
\text { (Estado } \\
\text { Miranda) } \\
\end{array}$ & 2017 & $\begin{array}{c}\text { Sí } \\
\text { (gastronomía) }\end{array}$ & Universidad & $\begin{array}{l}\text { Julio } \\
2018\end{array}$ \\
\hline E7 & 41 & $\mathrm{M}$ & $\begin{array}{l}\text { Cumaná } \\
\text { (Estado } \\
\text { Sucre) }\end{array}$ & 2016 & $\begin{array}{c}\text { Sí } \\
\text { (gastronomía) }\end{array}$ & Terciario & $\begin{array}{c}\text { Noviembre } \\
2018\end{array}$ \\
\hline E8 & 42 & $\mathrm{M}$ & $\begin{array}{c}\text { Acarigua } \\
\text { (Estado } \\
\text { Portuguesa) } \\
\end{array}$ & 2018 & $\begin{array}{l}\text { No (Sólo } \\
\text { chagas) }\end{array}$ & Universidad & $\begin{array}{c}\text { Diciembre } \\
2018\end{array}$ \\
\hline E9 & $30-40$ & $\bar{F}$ & $\begin{array}{l}\text { Maracay } \\
\text { (Estado } \\
\text { Aragua) }\end{array}$ & 2018 & $\begin{array}{c}\text { No } \\
\text { (Sólo } \\
\text { changas) }\end{array}$ & Universidad & $\begin{array}{l}\text { Enero } \\
2019\end{array}$ \\
\hline E10 & 36 & $\mathrm{~F}$ & $\begin{array}{c}\text { Anaco (Estado } \\
\text { Anzoátegui) }\end{array}$ & 2018 & $\begin{array}{c}\text { Sí } \\
\text { (cuidado } \\
\text { de personas) }\end{array}$ & $\begin{array}{c}\text { Terciario, } \\
\text { Universidad } \\
\text { incompleta }\end{array}$ & $\begin{array}{l}\text { Enero } \\
2019\end{array}$ \\
\hline E11 & $30-40$ & $\mathrm{~F}$ & $\begin{array}{l}\text { Anaco (Estado } \\
\text { Anzoátegui) }\end{array}$ & 2018 & $\begin{array}{c}\text { No } \\
\text { (busca) }\end{array}$ & Terciario & $\begin{array}{l}\text { Enero } \\
2019\end{array}$ \\
\hline E12 & 26 & $\mathrm{~F}$ & Caracas & 2018 & $\begin{array}{c}\text { Sí } \\
\text { (emprendimie } \\
\text { nto propio) }\end{array}$ & Universidad & $\begin{array}{c}\text { Febrero } \\
2019\end{array}$ \\
\hline E13 & 31 & $\mathrm{M}$ & Caracas & 2018 & $\begin{array}{c}\text { Sí } \\
\text { (emprendimie } \\
\text { nto propio) }\end{array}$ & Universidad & $\begin{array}{c}\text { Febrero } \\
2019\end{array}$ \\
\hline E14 & 38 & $\mathrm{~F}$ & $\begin{array}{l}\text { Anaco (Estado } \\
\text { Anzoátegui) }\end{array}$ & 2017 & $\begin{array}{l}\text { Sí (empleada } \\
\text { de comercio) }\end{array}$ & $\begin{array}{l}\text { Universidad } \\
\text { incompleta }\end{array}$ & Junio 2019 \\
\hline E15 & 37 & $\mathrm{~F}$ & $\begin{array}{c}\text { Anaco (Estado } \\
\text { Anzoátegui) }\end{array}$ & 2018 & $\begin{array}{c}\text { Sí } \\
\text { (empleada } \\
\text { de comercio) }\end{array}$ & $\begin{array}{l}\text { Universidad } \\
\text { incompleta }\end{array}$ & $\begin{array}{c}\text { Agosto } \\
2019\end{array}$ \\
\hline
\end{tabular}

Fuente: elaboración propia.

La crisis de la década de los ochenta -que incluyó devaluación monetaria, deuda externa, caída del precio del crudo- culminó en 1989 en el evento conocido como "el caracazo", con saqueos, toque de queda y más de 200 personas fallecidas (De La Vega, 2005). Esta crisis motivó el retorno de algunos y algunas inmigrantes a sus países de origen. Luego de la asunción del presidente Hugo Chávez Frías en 1999 (1999- 2013) comienza la emigración de venezolanos y venezolanas profesionales e investigadoras (Freitez, 2011; Mateo y Ledezma, 2006; Panadés Inglés, 2011; Requena y Caputo, 2016; Romero et al., 2016) y, según los datos estadísticos del Patrón Electoral en el 
extranjero, opositores y opositoras al gobierno chavista (De La Vega y Vargas, 2014). Funcionarios, funcionarias y profesionales de la oposición, de clase alta y media alta caracterizaron entonces el perfil de la primera oleada migratoria venezolana (Koechlin et al., 2018). Partieron mayoritariamente hacia los Estados Unidos de América, España y Francia y se auto consideraban como personas exiliadas (Guardia Rolando, 2007; Roniger, 2010). Según la literatura consultada, esta emigración estuvo motivada para los protagonistas por ciertas medidas políticas, como el despido masivo de 20.000 trabajadores de PDVSA, la confección de "listas negras" de opositores y opositoras (como la lista de Tascón o de Maisanta), la entrega de alimentos en función de la afiliación política, etcétera.

A partir del referéndum por la reelección indefinida en el año 2007, de las medidas de expropiaciones de tierras y empresas y de la estatalización de canales de televisión contrarios al régimen, comenzó a emigrar otro grupo de ciudadanos y ciudadanas venezolanas. Esta segunda ola estuvo conformada por personas pertenecientes a las clases medias y altas, profesionales, empresarios y empresarias que decidieron abandonar el país y mudar asimismo sus empresas, generando una notoria fuga de capitales.

El presidente Nicolás Maduro (2013- presente) profundizó algunas políticas previas, entre las que se destacan el control de precios, la devaluación del bolívar y la promulgación de la Ley de precios Justos, que fomentó el cierre de casi 78.000 empresas en Venezuela (Castillo Crasto y Reguant Álvarez, 2017). En un contexto nacional signado por una inflación descontrolada, el desabastecimiento de alimentos, artículos de higiene y medicamentos (que conlleva un auge del mercado negro) y la violencia organizada y generalizada (Freitez, 2011), se sucedieron la tercera y la cuarta ola migratoria. A partir del 2013, son los ciudadanos y ciudadanas de clase media, en su mayoría con estudios universitarios y terciarios, que deciden partir en busca de mejores condiciones para desarrollar sus profesiones. Según sus posibilidades, eligieron los destinos tradicionales o los países latinoamericanos. Esta oleada responde a la caída en la pobreza de las clases medias "tradicionales" (que eran clase media antes de la presidencia de Chávez), según el estudio de Hernández (2016). La cuarta ola, finalmente, se observa desde al año 2016 y estaría conformada, según los y las autoras consultadas, por personas de clase media y baja en busca de trabajo o ingresos para sobrevivir. En este caso, la emigración está dirigida hacia los países cercanos, especialmente Colombia (48.714 venezolanos en 2015 y 676.093 en 2019 según ACNUR), Brasil (5.00o en 2015 y 74.860 en 2019), así como el resto de los países de Sudamérica. 
En este contexto, las primeras investigaciones sobre la reciente migración venezolana en Argentina dan cuenta de la alta incidencia de profesionales (Pacecca y Liguori, 2019; Pedone et al., 2019)5, una inserción laboral en sectores informales o precarizados (Pedone y Mallimaci, 2019) y su concentración en las grandes ciudades (Biderbast y Nuñez, 2018). Estos trabajos establecen que uno de los factores de atracción es la posibilidad de radicación y de permanecer en Argentina de manera regular, gracias a las facilidades brindadas por la Ley de Migraciones 25.871 (2004) y al Acuerdo de Residencia para los Nacionales de los Estados Partes y Asociados del MERCOSUR (2002)6.

En cuanto a nuestra área de estudio, se trata de un aglomerado urbano que se corresponde con una ciudad intermedia, conformado por la ciudad de Santa Rosa, que es la capital de la Provincia de La Pampa y la ciudad más poblada de la provincia, con 103.241 habitantes según el Censo 2010, y su ciudad satélite, Toay, de 12.134 habitantes, que se encuentra a $8 \mathrm{~km}$ de la capital. El último registro censal del año 2010 indicaba que La Pampa contaba con 3447 habitantes que habían nacido en el extranjero, cifra que representa el 1,08\% de su población total y la ubica muy por debajo de la media nacional, que asciende al 4,5\%. No obstante, en la última década ha recibido nuevas corrientes migratorias entre los que se destacan los venezolanos (Linares, 2020). Este aumento fue significativo especialmente desde el año 2016, como se puede observar según las radicaciones resueltas por la DNM para la provincia, como figura en la Figura 1:

\footnotetext{
5 Sobre la cualificación de la emigración venezolana como problema de investigación desde la perspectiva de la "fuga de cerebros" con dirección Sur-Norte (Pedone y Alfaro, 2018), ver Requena y Caputo (2016) para el período 1960-2016, sobre la emigración de intelectuales. De la Vega (2005) analiza el período 1980 - 1990 y De la Vega y Vargas (2014) lo amplían hasta 2014. Allen y Fazito (2017) analizan los stocks de migrantes calificados venezolanos en el período 2001 - 2011. Para profundizar sobre el análisis de la "fuga de cerebros" de personas venezolanas ver también Freitez (2011), Panadés Inglés (2011), Mateo y Ledezma (2006), Romero et al. (2016) y Baldwin (2017). Un análisis de la migración selectiva se encuentra en el trabajo de Sala (2019), para el caso de los ingenieros venezolanos en Argentina.

${ }^{6}$ La Ley de Migraciones $\mathrm{N}^{\circ} 25.871$ contempla la perspectiva de los derechos humanos y tiene un enfoque migratorio regionalista al aplicar el criterio de nacionalidad para la residencia temporaria (Arts. 23 y 28) que beneficia a los ciudadanos del Mercosur y asociados. El Acuerdo de Residencia para los Nacionales de los Estados Partes y Asociados del MERCOSUR fue firmado en el año 2002 y reconocido por la Ley 25.902 de la república Argentina. Este acuerdo equipara los requisites para obtener residencia legal por parte de cualquier persona de un país miembro en otro país del bloque. Además de estos instrumentos normativos, desde el año 2018 el Estado Argentino, mediante la Dirección Nacional de Migraciones y otros organismos, han promovido una serie de políticas migratorias selectivas destinadas a la población migrante proveniente de Venezuela: programas de regularización migratoria (Disposición 594/2018 y 520/2019 de la DNM), reconocimiento de títulos educativos y convalidación de títulos universitarios (Resolución 230-E y 232E/2018 del Ministerio de Educación), programas de protección a los DDHH (Resolución 511/2019 del Ministerio de Justicia y Derechos Humanos), entre otros.
} 


\section{Figura 1. Permisos de residencias totales otorgados en la Provincia de La Pampa, 2004 - 2018}

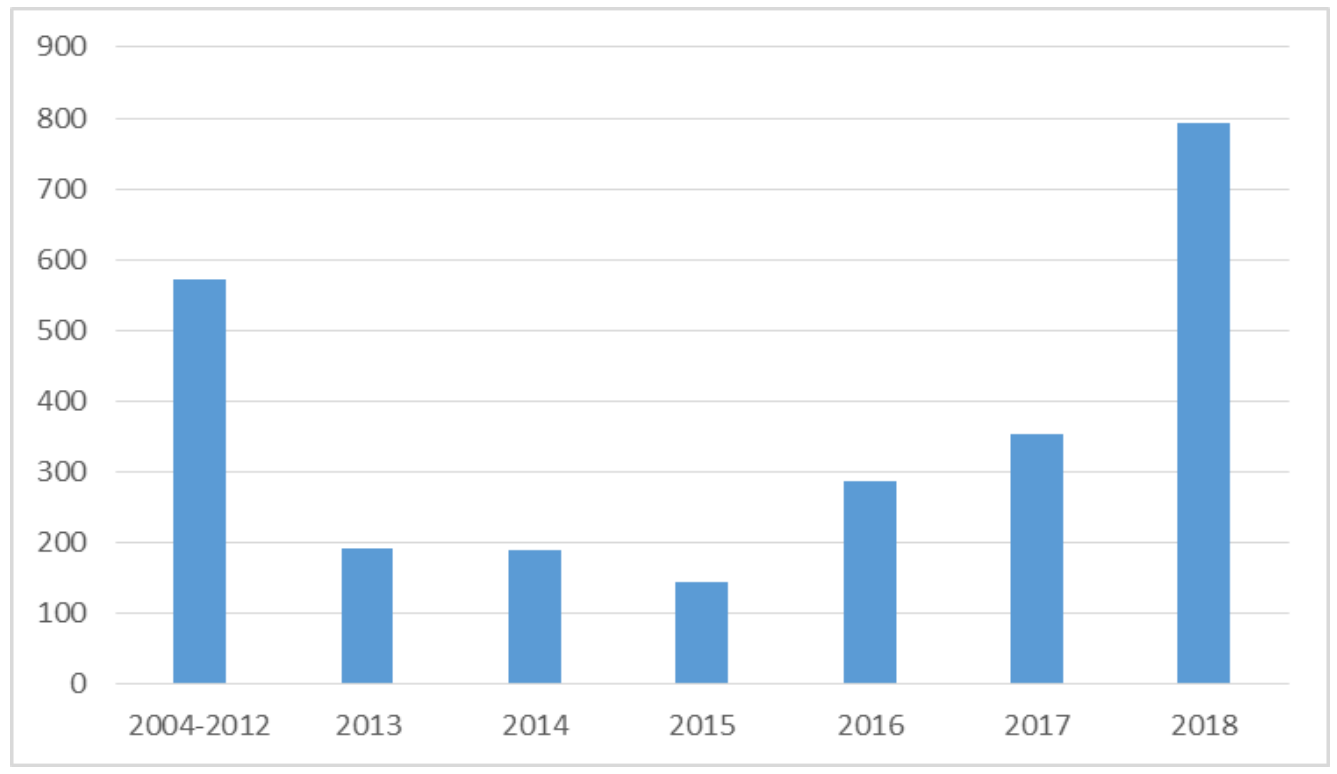

Fuente: elaboración propia a partir de datos de la DNM Estadísticas (http://www.migraciones.gov.ar/accesible/indexA.php?estadísticas) y del MEMO $\mathrm{N}^{\circ}$ 10683/2013, Nota $N^{\circ}$ 2221/2013, Buenos Aires, o9 de septiembre de 2013

Sobre la cantidad de ciudadanos y ciudadanas venezolanas que residen en la provincia, un alto funcionario de la DNM Delegación La Pampa7 confirmó que en el año 2018 realizaron 307 los trámites de residencia y en el año 2019 solicitaron 122 hasta agosto. Hay que tener en cuenta que estos números no reflejan la realidad de residentes en la provincia por tres razones: 1- se trata de todos los trámites iniciados, que incluyen los pedidos de prórroga, lo que habilitaría un doble conteo, 2- dado que en esta delegación los turnos son otorgados en un día, son numerosos los casos de personas que habitan en otras provincias que viajan a La Pampa para realizar sus trámites y luego regresan a sus lugares de residencia y 3 - también hay casos donde inician el trámite pero luego se mudan a otros lugares del país. Es importante notar que, según las entrevistas a funcionarios y funcionarias, en el año 2018 los pedidos de residencia de personas provenientes de Venezuela superaron a las nacionalidades más tradicionales: la paraguaya y boliviana. Para los y las migrantes entrevistadas, sin embargo, son aproximadamente 150 los y las que residían en Santa Rosa-Toay en el año 2019 (según sus redes de contactos). Excepto dos migrantes que llegaron en el año 2010 (por causas que podrían denominarse "por amor", siguiendo a Roca Girona et al., 2012), todos los demás arribaron a la Argentina entre el 2016 y el 2018.

\footnotetext{
7 Entrevistas a alto funcionario DNM, Delegación La Pampa. Realizadas en los años 2018 y 2019, Santa Rosa.
} 
Este aglomerado urbano ofrece tres características atractivas para los y las migrantes entrevistadas: una red de contactos, "mayor tranquilidad" en relación a las metrópolis y facilidades para obtener la residencia temporal o permanente. La mayoría emigró de su país por una sensación de privación generalizada, en algunos casos de medios para la subsistencia, de alimentos, de medicamentos, otros casos por haber sido víctimas de inseguridad. Algunos llegaron a La Pampa luego de vivir en otros países y también en otras ciudades de la Argentina (migración por etapas), mientras que dos tercios de los y las entrevistadas tenían a La Pampa como destino final antes de emigrar. Casi ninguna persona entrevistada había pensado en migrar antes de decidir su trayectoria y muchas contemplan la posibilidad de retorno a su país, aunque no lo consideran probable en el corto plazo. A continuación, indicaremos las características principales de la inserción laboral y la utilización de redes sociales migratorias que habilitaron sus trayectorias.

\section{Resultados}

5.1. Trayectorias laborales: precariedad laboral pese a altos niveles de formación académica y profesional

En los relatos sobre la trayectoria laboral de migrantes provenientes de Venezuela en La Pampa se evidenciaron dos temas/problemas: a- el quiebre profesional producto de la migración y b- la informalidad a la hora de conseguir el primer e incluso todos los empleos y la precariedad laboral. Estas características son similares a las encontradas por otras autoras en el caso de la Ciudad Autónoma de Buenos Aires (Pacecca y Liguori, 2019; Pedone y Mallimaci, 2019; Pedone et al., 2019). Sin embargo, en estos trabajos se identifican dos tipos de perfiles de inserción laboral que se diferencian de acuerdo al período de arribo al país: pioneros/as y recién llegados/as. En ese sentido, en el caso pampeano no encontramos estas diferencias dado que, como explicamos anteriormente, de las 15 personas entrevistadas, 13 habían arribado al país luego del 2016, correspondiendo a la cuarta ola migratoria según Koechlin et al. (2018). Las 2 personas que arribaron antes de 2013 (pioneros/as) tuvieron, como veremos a continuación, una trayectoria laboral similar a sus connacionales.

Sobre el quiebre en la trayectoria laboral, la mayoría de las personas entrevistadas tenían trabajo en Venezuela y habían finalizado estudios universtarios o tecnicaturas. Ocho de ellas se ocuparon de legalizar sus diplomas mediante la Apostilla de La Haya en su país de origen con la esperanza de obtener, en el país de destino, un empleo acorde a su profesión o similar al realizado en Venezuela. Pese a este alto nivel de calificación académica y experiencia de inserción laboral profesional en su país de 
origen, analizar a este flujo migratorio como "migración cualificada" presenta inconvenientes ya que estos factores no implican una inserción acorde en los países de destino. Este problema es explicado por los y las protagonistas por tres motivos: a) la intención o no de continuar con la misma línea en la trayectoria migratoria, b) el reconocimiento o no de sus títulos por parte de los posibles empleadores y la validez de los mismos para obtener empleos de menor cualificación.

Algunas de las peronas entrevistadas, como el caso de E1 o E2, no deseaban obtener un trabajo acorde a su formación profesional debido a que querían cambiar de rubro, distinguiendo entre su "profesión” y su "oficio":

"Yo soy ingeniero metalúrgico y ejercía allá, trabajaba en el puerto (...) pero aquí no me interesaba porque ya conozco el trabajo, sé que es muy exigente y demandante y yo quería otra cosa, cambiar mi estilo de vida" (E1).

Sobre el reconocimiento legal de los títulos académicos, es preciso indicar que la República Argentina no tiene con Venezuela un convenio bilateral destinado a la convalidación y reconocimiento de títulos académicos. Sin embargo, desde al año 2018 el Ministerio de Educación argentino, mediante las Resoluciones E-230 y E-232, le orotgó preferencia a los trámites de validación de títulos académicos de ciudadanos y ciudadanas venezolanas. Con todo, como indican Pedone et al. (2019) para el caso de Buenos Aires, no hemos podido comprobar que estas medidas hayan tenido algún efecto en los y las migrantes que residen en Santa Rosa-Toay hasta el momento de la escritura de este artículo. De las 15 personas entrevistadas nunguno realizaba un trabajo acorde a su formación académica-profesional. Dos personas estaban buscando un empleo de su profesión (médicos) pero no lograban la convalidación de sus títulos por no poseer la Apostilla de La Haya:

"Yo soy pediatra especializado en nefrología infantil (...). Aquí trabajé en un geriátrico, pero no como médico sino limpiando y también hice "changas" como dicen ustedes: cortando césped, me ha tocado hacer muchas cosas locas, hasta pintar cabello, pasar coleto (trapo)!" (E8).

El resto de las personas entrevistadas, aún cuando sus títulos habían sido legalizados mediante la Apostilla, no hacían uso de ellos porque necesitaban con urgencia conseguir empleo y no querían demostrar que estaban sobrecalificados: "Yo era administrativa en una empresa y había estudiado en un Instituto Universitario tecnológico (...) pero aquí si muestras tu título de administración no puedes buscar para limpiar casas o para ser niñera, porque no tienes experiencia más que en administración” (E5). Como explica E3: 
"Estuve un año buscando trabajo (...) ahora trabajo como secretaria (...). Cuando trabajé en administración (en Venezuela) estuve en Recursos Humanos y no contratábamos a personas más calificadas para puestos menores porque siempre estarían buscando otros trabajos, algo en su rubro. A mí me pasó eso acá” (E3).

Entonces, más allá de la situación legal de sus títulos acdémicos, en general la trayectoria laboral de las y los migrantes venezolanos en La Pampa estuvo caracterizada por una ruptura con una línea que mantenían por varios años y por la que habían realizado muchos esfuerzos, como es el caso de E10;

"Soy técnica universitaria en Ingeniería en Seguridad Industrial y además estaba estudiando Derecho. (...) aquí trabajo en un geriátrico, en limpieza" (E10).

Las trayectorias previas a la migración le imprimen una idea promisoria en cuanto a expectativas que tal vez no se puedan alcanzar:

"Yo siempre trabaje en radio. Acá empecé a buscar y era un poquito difícil la cosa (...) metí papeles por todos lados y me llamaron de un retorant, empecé ahí como bachero (lavacopas)” (E7).

Pedone y Mallimaci (2019), tomando el concepto de clase y el punto de inflexión que supone la migración hacia la Argentina, nos proponen reflexionar sobre el desclasamiento social y económico, tanto material como simbólico, a partir de algunos criterios referenciales de las y los sujetos. La inserción laboral precaria en relación con el nivel de instrucción en el país de origen puede indicar un proceso de desclasamiento social, especialmente teniendo en cuenta las expectativas previas de los y las migrantes.

Pese a este problema que aparece como una constante, encontramos una característica peculiar en este tipo de migrantes internacionales: una vocación de "cuentapropismo" pujante. En varias de las trayectorias laborales reconstruidas observamos que, una vez pasada la primera etapa de arribo y comenzada la etapa de la estabilización a partir del primer empleo, se ideaban proyectos de negocios propios. dos con talleres o cursos, otro con la elaboración de materias primas para gastronomía. Dos pusieron locales abiertos al público; una un "negocio [gimnasio] abiero hace unos meses, en mi oficio" (E2) y otro una panadería. Otros buscaron la manera de sobrevivir, uno, por ejemplo, "como no me podía parar y estaba sin trabajo, me puse a fabricar insumos para comida venezolana, buscar proveedores, compradores, precios (...)" (E6). De la misma manera, otros encontraron la forma de conseguir alojamiento a cambio de diversos servicios: 
"Damos talleres para emprendedores, de marketing, por unos enlaces que hicimos con la Secretaría de Desarrollo Local de la Municipalidad, a cambio de estadía en el albergue municipal. No nos pagaban (...) a partir de los contactos con los emprendedores conseguimos un departamento para alquilar y empezamos a subir las charlas a redes sociales $\mathrm{y}$ generamos un ingreso así” (E11).

En relación con la segunda caracteristica encontrada, en todas las entrevistas realizadas se remarca el grado de informalidad en la obtención de empleo, que sólo en tres casos (E1, E4 y E7) se realizaron por vías "institucionales" (presentación de CV, carta de motivación, entrevista personal/grupal, concurso, etc.). Una de las entrevistadas explica:

“en la parrilla (restaurante) trabajé un año y un mes, en negro, mi marido también estaba en negro...y luego por un contacto pude entrar en una panadería” (E14).

Los contactos, aunque sean eventuales, fueron siempre decisivos a la hora de conseguir empleo:

"hablando con el chico del kiosco aquí en Toay me preguntaba si había conseguido trabajo (...) y una persona llegó en ese momento. Él me preguntó qué sabía hacer y le dije: depende, en construcción, no le iba a decir que era ingeniero! (...) con él trabajé hasta hace dos meses” (E6).

Encontramos entonces ingenieros en hidrocarburos, médicos, gerentes en Recursos Humanos, empleados administrativos, docentes y pequeños empresarios realizando labores de menor cualificación, entre los que se destacan: atención al público en comercios, gastronomía (lavacopas, meseos/as), cuidado de personas (adultos mayores y menores de edad), trabajadores de casas particulares, empleados de la construcción, jardinería, empleados de limpieza en instituciones, etcétera. El caso de E9 también es ilustrativo:

"Daba clase de matemática y era funcionaria de un instituto de educación para adultos (...) yo aquí cuido a una señora mayor, en negro" (E9).

Estos empleos se caracterizan por su alta incidencia de inserción en el mercado de trabajo precarizado: no regulado, no registrado ("en negro"), trabajos temporarios (“changas") y de bajos salarios. Frente al desempleo, los contactos son fundamentales: 
"yo estaba buscando, me metía en las páginas de buscadores de trabajo, pero nada... (...) Actualmente estoy trabajando como secretaria gracias a una amiga que me contactó" (E3).

Esta caracterísitca revela la importancia del papel facilitador que juegan las redes sociales en el país de destino y de las dificultades que eso implica para los recién llegados:

"El tema laboral aquí es un poquito restringido porque si tu no vienes recomendado o no conoces a nadie simplemente te dan la espalda, pues. Ni siquiera en lo mío, así sea para atender en una tienda te piden referencias, imagínate" (E13).

Por último, debemos destacar que en casi ningún caso los y las entrevistadas fueron discriminados/as por su condición de no-nacional en los ámbitos laborales. Este indicador remite a condiciones tanto objetivas como subjetivas, dado que se trata de la percepción de discriminación por la condición de extranjero o no-nacional. El término xenobofia hace referencia al miedo al extranjero y resulta finalmente en actos de discriminación basados en prejuicios culturales, religiosos, políticos y/o étnicos. Históricamente, la xenofobia en tanto discriminación ha sido utilizada discursivamente en la Argentina tanto por los medios de comunicación como por discursos políticos, para encontrar "culpables" de las crisis económicas o de la inseguridad. La idea del migrante como amenaza o como competencia por los empleos y recursos alimenta estos discursos que se transforman, en ocasiones, en actos de discriminación explícitos.

En este sentido, resulta interesante notar que los estereotipos y los prejuicios construidos (o, mejor aún, en construcción) sobre las y los venezolanos eluden las marcas negativas con las que tradicionalmente se ha discriminado a ciertos colectivos migrantes en Argentina. Son las poblaciones de países limítrofes y de Perú las que, hace ya más de medio siglo, sufren de discriminación y xenofobia en la Argentina (Halpern, 2006). Sin embargo, se pueden rastrear diferentes criterios de selectividad y exclusión en la política migratoria que han sostenido, históricamente, las ideas del buen y mal migrante según sus características (laborales, de origen, género, sanitarias, ideológicas, etcétera) (Biernat, 2007; Devoto, 2003; Pereira; 2019). Las representaciones sobre las y los migrantes venezolanos parecen, por el momento, estar más vinculados a la idea del migrante "deseable" por su alto nivel de calificación o, como relatan las personas entrevistadas, por su buen trato con la gente. En general, han experimentado algún tipo de discriminación positiva a la hora de buscar trabajo por la valoración positiva de su acento, porque son considerados cordiales y dispuestos al trabajo, como relata E1: 
"Creo que me dio siempre un plus (...) un día un jefe me dijo: - tu acento es un gancho, una ventaja, lo peor que te puede pasar es que pierdas tu acento".

Sólo en pocos casos han relatado sobre comentarios de discriminación negativa aislados de algún compañero de trabajo o de clientes como en el caso de E6:

"Un día vino una persona allegada al dueño del restaurant y dijo (...) que los extranjeros tenían que comportarse de manera excepcional porque sino los iban a deportar!”

Otras personas se sintieron discriminadas por las fuerzas de seguridad:

“Estuve presa (...) los policías cuando vieron mi Documento Nacional de Identidad pensaron que era falso y me tuvieron dos horas detenida, esa fue la experiencia más fea” (E5).

Aunque estos episodios fueron experimentados en cada caso como excepcionales, cada persona entrevistada nos relató uno o dos episodios de discriminación de algún tipo, o de situaciones confusas, como el caso de E4:

"Una sola vez me pasó, en la tienda, tuve una compañera de trabajo (...) que me dijo: iojalá que algún día te vuelvas a tu país! (...) Pero más bien he sentido mucha reciprocidad de la gente, que cuando te ve te pregunta, te dan la bienvenida a este país, te desean que te vaya bien (...) y mira que yo no soy como mi marido, que es blanco como tu. Yo soy morena, más gruesa (...) un hombre en el trabajo me dijo que parezco una mujer tropical. Pero lo dijo bien, con respeto" (E4).

Para concluir esta sección, estimamos interesante destacar dos cuestiones. Por un lado, los dos temas/problemas descubiertos en torno a la trayectoria laboral no significaban, para las personas entrevistadas, una frustración definitiva con respecto a los proyectos y expectativas previas a la migración. Casi la mitad de los y las migrantes remarcaban que su situación era transitoria, que luego vendría una etapa más estable o la posibilidad de retorno o incluso de continuación de sus trayectorias migratoria hacia otros países.

"Yo me saqué el famoso 'chip venezolano' que dice 'no, no voy a ir a trabajar pasando coleto (trapo), porque en Venezuela no lo hacía' (...). Yo ese chip lo dejé en Venezuela y desde antes de salir me dije: - voy a ese país a hacer lo que sea, con tal de crecer, de vivir bien, de que mis hijos tengan una buena calidad de vida, que puedan comer todos los días 
un buen plato de comida, que pueda comprarles un par de zapatos cada tres o cuatro meses ¿Me entiendes? Cosas que allá no podía hacer.” (E4).

Estas posibilidades abiertas relativizan la propia evaluación sobre sus trayectorias laborales en términos del quiebre en la trayectoria laboral o la precariedad laboral experimentada. Además, la sensación de "estado provisorio" que vivenciaban servían para justificar y aceptar diferentes precariedades en pos de objetivos ulteriores. Dentro de estos objetivos, el más importante era lograr la reunificación familiar, es decir, lograr traer a sus hijos, a sus parejas y hasta, en algunos casos, a sus padres (sobre todo a quienes vivían solos o solas) a la Argentina (Linares, 2020). Cabría preguntarse aquí si esta sensación de provisoriedad, como advierte Sayad (2010) se mantendrá en el tiempo como modo de resistir las exclusiones intrínsecas a la condición migrante.

Por otro lado, como indicamos en el apartado teórico, el análisis de las posiciones que ocupan las y los sujetos profundizaría el análisis de las trayectorias laborales, como veremos con mayor detenimiento en la proxima sección. En estas variables analizadas no hemos notado, como si lo hicieron Pacecca y Liguori (2019) o Pedone et al. (2019), una inserción laboral claramente diferenciada según roles de género. Excepto por el rubro de la construcción (uno de muestros entrevistados y los maridos de tres de nuestras entrevistadas), no se observa una marcada división sexual del trabajo como en el caso de la ciudad de Buenos Aires, donde las autoras evidencian una inserción laboral mayormente fenemina en el rubro de la cosmetología o el ciudado de personas, por ejemplo. De hecho, en las entrevistas realizadas en La Pampa tanto hombres como mujeres han compartido los mismos empleos: ciudado de personas, limpieza en instituciones y en casas particulares, jardinería, gastronomía, etcétera. La escasa cantidad de migrantes y los lazos establecidos a partir de las redes sociales migratorias han resultado en la circulación, no sólo de información sobre empleos, sino de los empleos mismos: cuando una persona dejaba uno lo ocupaba un o una compatriota por su recomendación, sin distinción de género. Además, los episodios de discriminación relatados hacían referencia, en todos los casos, solamente a la condición de "nonacional” y no se cruzaban con otras categorías, como el género o la raza/etnia.

\section{2. Redes sociales migratorias: de la virtualización al "cara a cara"}

En las entrevistas realizadas hasta ahora comprobamos que las trayectorias residenciales y laborales no se elaboran en soledad, sino que aparecen como etapas en un entramado social que habilita la inserción en la sociedad de destino. Aquí se manifiesta la importancia del papel que juegan las redes sociales al momento de vehiculizar la migración internacional hacia La Pampa, facilitando información, 
contactos, recursos económicos, alojamiento y vehiculizando los proyectos individuales de manera colectiva. Se evidencia, sobre todo, en los casos de migraciones por amor porque la idea de formar una pareja ya implica un proyecto de vida que excede a las decisiones individuales. Pero también en las migraciones familiares, en las cuales un miembro emprende la trayectoria como pionero/a para luego gestionar el arribo del resto del grupo familiar.

Notamos una escasa utilización de redes migratorias con cierta "institucionalidad" o establecidas previamente: ninguna de las personas entrevistadas manifestó conocer instituciones o grupos de personas que viabilizaran la migración hacia Argentina o hacia La Pampa de manera organizada antes de su decisión de migrar. Pero en cada uno de los casos vimos cómo la movilidad hasta La Pampa puso en juego un abanico de recursos sociales que, al sistematizarlos para el fin migratorio, comienzan a entramar una red que podría ser útil para otros proyectos migratorios más adelante. Algunos conocieron a personas de La Pampa en redes sociales virtuales, otros en su país de origen y otros ya tenían compatriotas viviendo en la provincia. Al momento de decidir su trayectoria migratoria, estas primeras relaciones directas o indirectas se tornaron fundamentales. Distinguimos entonces tres tipos de redes que en ocasiones aparecen combinadas: las virtuales, la red local -por iniciativa de E1 a partir de un grupo de whatsapp- y las redes basadas en apoyos personales con relaciones directas, en general de parentesco o amistades fuertes, organizadas a partir de contactos previos. Como veremos más adelante, hemos distinguido asimismo relaciones horizontales y verticales dentro de una misma red, según las posiciones de sus miembros.

Sobre las redes virtuales, todas las personas entrevistadas manifestaron hacer uso de grupos virtuales de características étnicas/nacionales identitarios en las "redes sociales" (Facebook, Twitter, por ejemplo). Estas redes facilitaron la información sobre los trámites en la DNM o para apostillar los títulos de estudio, las posibilidades de alojamiento y las oportunidades laborales en Argentina. La conexión se realizó con agrupaciones como ASOVEN, por ejemplo, o agrupaciones regionales, como indica E4:

"Por internet obtuve toda la información del papeleo que tenía que traer para acá. (...) me comencé a meter en grupos de facebook: "venezolanos en Argentina", "una mano de pana", "venezolanos en Córdoba", "venezolanos en La Plata”, hay varios.” (E4).

En un intermedio entre la red virtual y la de relaciones cara a cara, encontramos la alternativa local. Hallamos tres casos de migrantes que residían en otras áreas de la Argentina y que tomaron conocimiento de E1, quien se consolidó como centro de una red social migratoria local. Una de estas personas es E2: 
"Quería mudarme a una provincia porque sabía que se vivía más tranquilo. (...) Y por whatssap conseguí un grupo que estaba aquí. E1 lidera ese grupo por ser el primer venezolano que llegó aquí, a Santa Rosa. Y me comuniqué con él y me dijo que aquí era muy tranquilo: Vente que nosotros aquí te ayudamos y te apoyamos en todo lo que necesites... y nada, y aquí llegué” (E2).

De hecho, cada migrante proveniente de Venezuela llegado a la provincia o con intenciones de viajar a la Pampa se puso en contacto con E1 e ingresaron en algún momenton al grupo de whatsapp, donde se les ofrecía alojamiento transitorio o información relativa a los trámites documentarios, por ejemplo. El grupo funciona, según sus relatos, como un espacio de convivialidad:

"El único grupo que tenemos (los venezolanos en La pampa) es por Whatssap, estamos en contacto. A veces nos reunimos en casa de alguien” (E1).

También ha servido como un medio de ayuda: frente a la situación de incendio de la vivienda de un miembro del grupo, se movilizaron para conseguir elementos como heladeras, televisores, etcétera. Según estos relatos, podríamos indicar que la red no era mixta, ya que estaba compuesta exclusivamente por personas venezolanas. Sus relaciones eran tanto directas como indirectas (familiares, amistades o conocidos) y horizontales. Esto quiere decir que se basaban en la solidaridad entre compatriotas y si bien giraba en torno a una persona (el migrante más antiguo) no detectamos relaciones de poder, clientelares o asimétricas dentro de la red. Este grupo de whatssap, que en 2017 contaba con 16 miembros, al 2019 llegó a los 50 y fue una herramienta crucial en nuestra primera etapa de investigación porque, aunque nunca tuvimos acceso directo a él, por este medio se trasmitió la información sobre esta investigación, gracias al cual tres entrevistados accedieron a participar.

En algunos casos, gracias al pequeño universo de migrantes provenientes de Venezuela en La Pampa, pudimos reconstruir en su totalidad la red migratoria basada en apoyos personales y relaciones directas que habilitó la llegada de varios de nuestros entrevistados/nodos. Esta red comenzó con una amistad entre una mujer venezolana (E14) y un hombre pampeano (dos nodos iniciales) y en el transcurso de dos años se diversificó en doce nodos. La figura clave es la de Diego, un pampeano que ha colaborado personalmente con las trayectorias migratorias de tres de nuestros entrevistados que, a su vez, habilitaron las trayectorias de más parientes y amigos/as. En esta red encontraremos tanto relaciones horizontales como verticales. Nuestro primer contacto fue con E4, quien nos relató: 
"Mi amiga nos puso en contacto con una persona de acá, que también fue él que la ayudó a ella a venir, un gran amigo, en verdad lo quiero muchísimo, y él nos ayudó a venirnos acá a Santa Rosa. Mi amigo es argentino, el señor Diego. Por eso creo que se nos hizo más fácil, primero porque él nos dijo como era acá, que no era Buenos Aires, que era una provincia, un pueblo así y así (...) Hay un amigo de mi esposo y mi esposo lo ayudó a venirse para acá, es una cadena, viste? Y pronto va a llegar otra amiga. Y todos pasan por aquí, paran en mi casa y luego cuando consiguen algo se van... (...) Se-guimos siendo amigos de este primer contacto [Diego] y que dios guarde esta amistad por muchos años (...) cuando llegamos no teníamos tarjeta de crédito y él nos ayudó a comprar la heladera, luego nosotros se la pagamos en cuotas”. (E4).

Diego habilitó la llegada del esposo de E4 porque era el compadre de E14, le ofreció el primer empleo y le dio el dinero para lograr la reunificación familiar. Al momento de la llegada de E4 con sus hijos a la Argentina, Diego la fue a buscar al aeropuerto de Ezeiza. Diego también colaboró con el arribo de E5 y su familia, porque eran amigos de E4:

"al principio mi marido vivía con el marido de E4, luego empezó a coordinar con el señor Diego para que nosotros viniéramos y nos vinimos a los tres meses" (E5).

Finalmente, estas dos familias facilitaron el arribo de casi una veintena de personas más. Posteriormente conocimos, sin intervención de ningunos de los entrevistados (es decir, por fuera de esa línea de la bola de nieve), a E14, quien resultó ser la primera venezolana que llegó por intermedio de Diego. Ella nos relató que había conocido personalmente a Diego en un viaje de él a Venezuela y que, al momento de decidir migrar hacia la Argentina, lo contactó. Diego le consiguió trabajo y alojamiento a ella y a su marido:

"Yo fui la primera! A mí el señor Diego me pasó a buscar a Misiones [provincia de ingreso al país]! Después por mi vino el marido de E4 y ella se trajo a su hermano. El marido de ella se trajo a su compadre, y la mujer de él (E5) se trajo a su hermana y ella se trajo a unas sobrinas. Y todo es una raíz que cada quién se trae los suyo. Pero la raíz está aquí [se señala a si misma] Yo soy la raíz. iY a mí me encanta!” (E14).

En una entrevista, Diego accedió a contarnos sobre su rol como habilitador de las trayectorias migratorias que, sumados a los relatos de $\mathrm{E}_{4} \mathrm{y}$ E5, nos permitieron reconstruir los lazos de la red: 
"Y un día llegó (el esposo de E5) y yo tenía que hacer un pozo ciego y lo puse a hacer el pozo. Él llegó a la mañana y a la tarde nos fuimos a la obra (...) Aparte de que yo lo ocupé a él y al esposo de E4 trabajando, luego se generó como un conflicto, no sé, como de recelo, que los argentinos comenzaron a trabajar mejor. O sea, la hora-hombre de ellos (venezolanos) me rinde muchísimo más que la hora-hombre de un argentino" (Diego, 15/06/2018, Santa Rosa).

Hemos podido reconstruir y volcar en un gráfico (Figura 2) esta red social migratoria basada en apoyos personales y relaciones directas que, como establece E14, comenzó con la relación de amistad entre dos personas, ella y el "señor Diego" (nodos principales), y terminó con la llegada a Santa Rosa de doce nodos más. La reconstrucción se realizó a partir de unir los retazos de historias de varios de nuestros entrevistados que, más alejados o cercanos a los dos nodos centrales, tuvieron algún tipo de relación con dicha red. Por ellos supimos de los otros nodos de esa red a los que no llegamos a contactar. Los alcances de esta red transcienden los lugares de destino y van estableciendo nodos en el país de origen. Una muestra de ello es la cantidad de personas provenientes de Anaco (Estado Anzoátegui) arribadas a Santa Rosa en los últimos dos años que consolidan la red a nivel transnacional (origen/destino), como se observó en la Tabla 1.

Si bien la primera relación del nodo fue horizonal, dado que se trató de una amistad en Venezuela, podríamos establecer un giro a partir del arribo de esta familia a la Argentina. Como relatan, fue Diego quien les consiguió el primer trabajo como cuidadores de su madre, una persona mayor. Pronto les sugirió un contacto con el dueño de un restaurat, donde trabajaron en la cocina durante un año. Mientras tanto, E14 recomendaba a su compadre y a un amigo de él con Diego, quien los empleó en “changas” y ayudó con su instalación en Santa Rosa.

Entonces, teniendo en cuenta las posiciones de cada nodo en la red, se observa que en los relatos de E14, E4 y E5 existe un genuino agradecimiento hacia Diego, pero a su vez una diferenciación notable entre esta ayuda recibida por parte de un "amigo argentino" y la de sus compatriotas. La posición según la nacionalidad se evidencia como la primera distinción que denota una relación de poder/saber: el "señor Diego" conoce la ciudad, el país, informa sobre las diferencias entre Buenos Aires y La Pampa, los recoge en los aeropuetos o en la frontera, por ejemplo. Pero no sólo la nacionalidad y el conocimiento denotaban una relación vertical: las relaciones laborales patrón-peón de campo y el préstamo de dinero o pasajes, posicionaban a Diego en un lugar de poder evidente, aunque ejercido de modo paternal o fraterno. Los siguientes nodos formados 
a partir de las relaciones directas de E4, E5 y E14 con sus compatriotas se manifiestan como horizontales, donde primaban las relaciones familiares o de compadres y comadres que habitaban en sus hogares hasta que consiguieran vivienda propia. En los relatos sobre como se contruyen estas relaciones horizontales con los compatriotas se denota la alegría y el orgullo de poder colaborar con sus proyectos migratorios y de sentirse un eslabón de importancia en las "cadenas" o "raíces", según sus palabras. Nuevamente, como en el apartado anterior, en estas redes identificadas no evidenciamos un posicionamiento relativo al género que implique una relación asimétrica de poder entre los miembros de las redes. El factor decisivo de poder en estas dos variables analizadas ha sido la categoría de nacionalidad, que se ha mostrado como la más relevante en el posicionamiento de las y los sujetos entrevistados.

\section{Figura 2. Red social mixta}

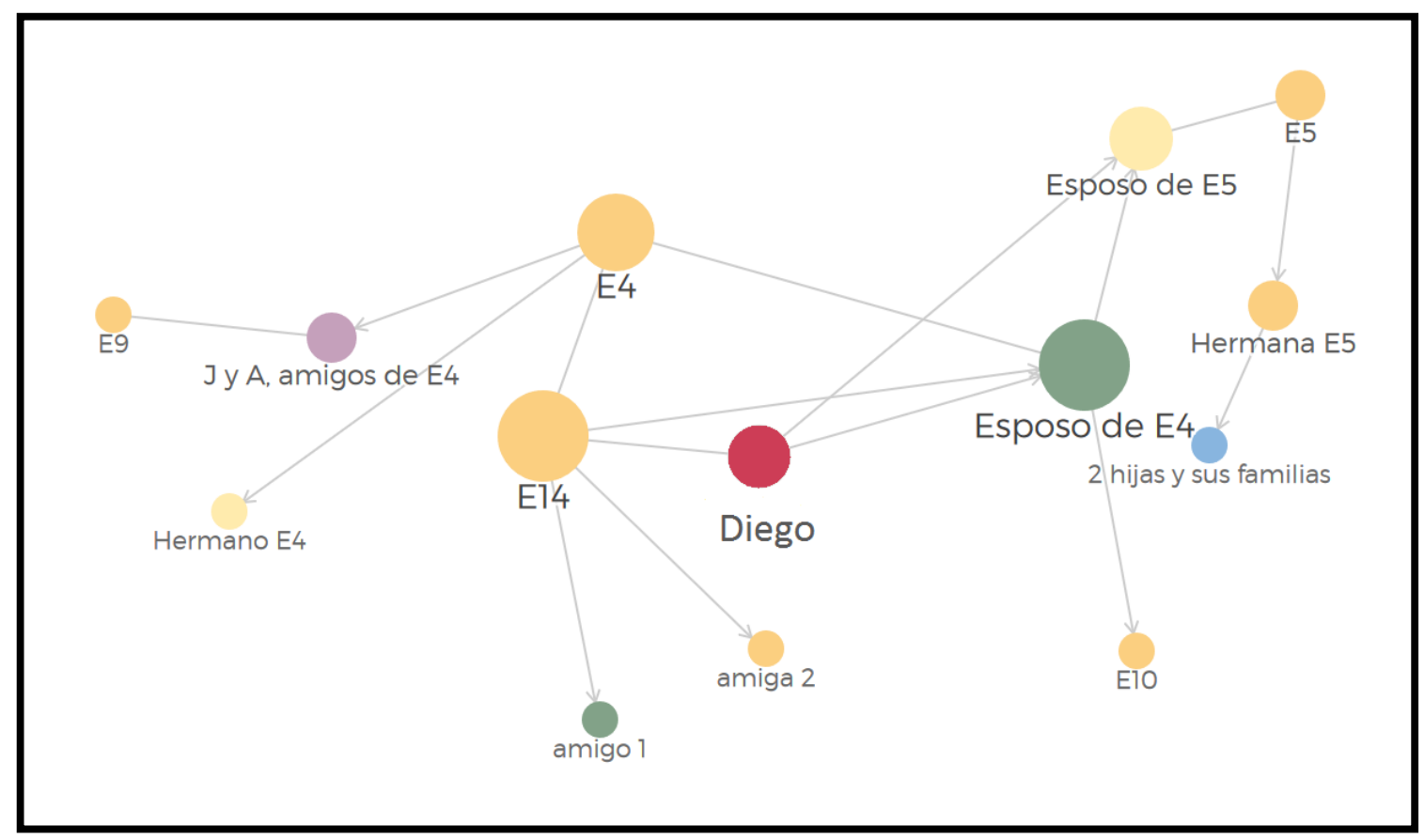

Fuente: Elaboración propia a partir de entrevistas realizadas a migrantes venezolanos/as en Santa Rosa-Toay. 


\section{Conclusiones}

En este artículo nuestro objetivo fue en indicar y describir algunas características de la migración venezolana hacia La Pampa entre los años 2010 y 2017, centrando el análisis en las trayectorias laborales y en las redes sociales que la habilitaron. A partir del cruce de nuestros resultados con los estudios relevados, hemos podido constatar que la mayoría de las y los migrantes arribados a Santa Rosa-Toay lo hicieron luego del año 2016 y salieron de su país mayoritariamente entre el 2013 y 2016, correspondiéndose a la tercera y cuarta ola migratoria. Si bien la elección del destino migratorio respondió mayoritariamente a la existencia de contactos previos (mixtos, tanto compatriotas como argentinos), muchas de las personas entrevistadas valoraron positivamente la facilidad para la regularización documentaria a la hora de decidirse por la Argentina.

Sobre la trayectoria laboral, es importante destacar que la gran mayoría de las y los migrantes tenían altos niveles de formación (títulos universitarios o terciarios) y, sin embargo, ninguna persona había conseguido todavía empleo en Argentina acorde a sus estudios. Tampoco habían logrado realizar, hasta el momento de redacción de este artículo, los trámites necesarios para convalidar sus títulos universitarios. Algunas habían decidido optar por actividades cuentapropistas relacionadas a otros intereses $\mathrm{u}$ “oficios". Otras personas entrevistadas estaban esperando poder apostillar sus títulos para iniciar los trámites de convalidación. Pero la gran mayoría no hacía uso de sus títulos porque los empleos a los que accedían eran de menor calificación, razón por la cual prefieren no informar sobre su sobrecalificación. Al igual que lo descubierto por Pedone y Mallimaci (2019), Pedone et al. (2019) y Pacecca y Liguori (2019), la inserción laboral en La Pampa se caracterizó por empleos precarios, de bajos salarios, temporarios y no registrados o “en negro”. La forma de encontrar empleo en Argentina se distinguió por la informalidad: en casi todos los casos fueron por contactos, lo que indica la importancia de las redes sociales migratorias para la obtención de empleo. Con respecto a las redes sociales migratorias, comprobamos que las redes virtuales, especialmente a través de plataformas como Facebook y Whatsapp, fueron utilizadas con el fin de obtener información una vez tomada la decisión de migrar hacia la Argentina. Los y las potenciales migrantes las utilizaron en busca de datos sobre los trámites en la DNM, información sobre oportunidades de empleo y de alojamiento. En Santa Rosa-Toay se fue organizando una red de migrantes de Venezuela alrededor de la figura de E1, que estiman fue el primero en llegar. La centralidad de la figura de E1 puede explicarse por su negocio de venta de productos venezolanos, que ha funcionado 
como un faro para los recién llegados a la ciudad. Siguiendo a Pedone (2010), pudimos comprobar que esta red se caracteriza por estar constituida por relaciones directas e indirectas, pero en todo caso horizonales. Por otro lado, pudimos reconstruir una red de alcance transnacional centrada en la figura de Diego que viabilizó personalmente la llegada de tres familias de venezolanos a La Pampa. A su vez, esas familias fueron haciendo llegar a más familiares y amigios/as en los últimos dos años, brindando no sólo información, sino alojamiento y, en algunos casos, empleos (espcialmente cuando uno dejaba un empleo y recomendaba a otro compatriota). Esta compleja red es mixta, formada por relaciones verticales y horizontales, cuya configuración de los posicionaminetos sociales a su interior está determinada fundamentalemnte por la categoría de nacionalidad y las relaciones laborales (empleado-empleador).

Indagamos también sobre las percepciones de discriminación, que se reiteraron en todas las personas entrevistadas, algunas -sólo dos- como discriminación positiva y otras como negativa. Pese a esta reiteración, fueron vivenciadas por cada individuo como fenómenos extraordinarios y originados por el "desconocimiento". El análisis de estas variables -inserción laboral, redes sociales y percepciones de discriminación- nos permiten reflexionar sobre las posicionalidades múltiples de los y las sujetos migrantes. Observamos, en el relato sobre estas vivencias, formas de posicionarse que cruzan, en la mayoría de los casos, cuestiones étinas/nacionales con raciales que indican la heterogeneidad aún dentro de un mismo colectivo migratorio (Guzmán Ordaz, 2009). Dentro de las categorías sociales advertidas por el Colectivo OIE (1996), estimamos que son las de nacionalidad, clase y raza las que afectan de manera interseccionada sus posicionamientos, y no tanto así la categoría de género (por lo observado hasta el momento en estas variables exclusivamente y no en otras). Los y las migrantes entrevistadas relataron detalladamente el desclasamiento social experimetndo como producto de la migración y reivindicaron su papel de trabajadores y de agentes de redes sociales destinadas a colabroar con las trayectorias migratorias de parientes y amigos. Por otro lado, manifestaron su agradecimiento hacia "la sociedad" de destino y a algunos ciudadanos argentinos en particular por su "ayuda" y buen trato, posicionándose en un lugar diferenciado verticalmente. En algunos casos, también se cruzó la categoría racial para determinar el lugar ocupado frente a una sociedad receptora percibida como racialmente diferente a la propia, aunque no se manifestó uan diferenciación jerárquica.

Finalmente, las características de las trayectorias laborales que se describieron en este trabajo podrían ser generalizables a otras ciudades argentinas, incluso grandes ciudades como la Ciudad Autónoma de Buenos Aires, Córdoba o Rosario. Pese a algunas herramientas que el Estado argentino destina a este colectivo migratorio, como 
el reconocimiento de su formación académica, por ejemplo, la precariedad y la informalidad fue, a lo largo de estos tres años, un rasgo imperante en la inserción de los venezolanos al mercado de trabajo argentino, rasgo que, como vimos, ha sido determinante en sus posicionamientos. Sin embargo, debemos considerar que se trata de un flujo migratorio masivo pero reciente, altamente calificado y que pertenece, en su mayoría, a la tercera y cuarta ola migratoria por su año de salida de Venezuela. Teniendo en cuenta estos factores y el contexto cambiante de la crisis venezolana que motivó la emigración, no podríamos afirmar que estamos frente a trayectorias migratorias permanentes sino temporarias, inconclusas o de circulación, en la etapa de instalación y no de establecimiento. Como explica el modelo teórico de las redes sociales migratorias, los flujos tenderían a estabilizarse luego de un auge y, en el caso venezolano, la estabilización social y económica del país podría dar un nuevo giro al patrón migratorio. El relato de los y las migrantes marcaba permanentemente este estado circunstancial de su trayectoria, de transitar un estado provisorio en el cual sus expectativas eran dejadas de lado por el escaso tiempo de residencia en la Argentina. En ese sentido, sólo una mirada de largo plazo podrá ser capaz de profundizar el análisis sobre los modos y alternativas de inserción laboral de los migrantes venezolanos en la Argentina y los cambios en la negociación de sus posicionamientos y del tipo de vinculación que se entable con la sociedad argentina.

\section{Referencias}

Allen, A. J. y Fazito, D. (2017). Mecanismos de selectividad y destinos principales de emigrantes argentinos y venezolanos: un análisis comparado. Notas de población, CEPAL, 105(XLIV), 191-220. Recuperado de: http://hdl.handle.net/11362/43166

Arango, J. (2003). La explicación teórica de las migraciones: luz y sombra. Migración y desarrollo, (1), 1-30.

Baldwin, L. (2017). The Venezuelan Diaspora: A Cerebral Exodus. . Latin American Studies: Student Scholarship \& Creative Works. Student Paper https://digitalcommons.augustana.edu/ltamstudent/1

Bastia, T. (2007). From mining to garment workshops: Bolivian migrants in Buenos Aires. Journal of ethnic and migration studies, 33(4), 655-669.

Biderbast, P. y Nuñez, M. E. (2018). Del Río de la Plata al Orinoco y viceversa. Patrones y flujos migratorios entre Argentina y Venezuela. J. y. E. R. Koechlin, Joaquín (Ed.), El éxodo venezolano: entre el exilio y la emigración,135-166. Madrid: 
Observatorio Iberoamericano sobre Movilidad Humana, Migraciones y Desarrollo.

Biernat, C. (2007). ¿Buenos o útiles?: la política inmigratoria del peronismo. Buenos Aires: Editorial Biblos.

Camacho, G. (2010). Mujeres migrantes. Trayectoria laboral y perspectiva de desarrollo humano. CLACSO: Buenos Aires.

Castillo Crasto, T. E. y Reguant Álvarez, M. (2017). Percepciones sobre la migración venezolana: causas, España como destino, expectativas de retorno. Migraciones, 41, 133-163. DOI: mig.i41.y2017.006

Colectivo OIE. Actis, W., De Prada, M. A., y Pereda, C. (1996). ¿Cómo estudiar las migraciones internacionales? Migraciones. Publicación Del Instituto Universitario De Estudios Sobre Migraciones, 7-23. Recuperado a partir de https://www.razonyfe.org/index.php/revistamigraciones/article/view/5004

De la Vega, I. (2005). Mundos en movimiento: movilidad y migración de científicos y tecnólogos venezolanos. Caracas: Fundación Polar.

De la Vega, I. y Vargas, C. (2014). Emigración intelectual y general en Venezuela: una mirada desde dos fuentes de información. Revista Electrónica Latinoamericana de Estudios Sociales, Históricos y Culturales de la Ciencia y la Tecnología, (1), 66-92.

Devoto, F. (2003). Historia de la inmigración en la Argentina. Buenos Aires: Sudamericana.

Domenech, E. (2009). Migración y política: el Estado interrogado. Procesos actuales en Argentina y Sudamérica. Córdoba: Universidad Nacional de Córdoba.

Freitez, A. (2011). La emigración desde Venezuela durante la última década. Revista temas de coyuntura, (63), 11-38.

Garduño, E. (2003). Antropología de la frontera, la migración y los procesos transnacionales. Frontera Norte,15(30), o. Recuperado de: http://www.redalyc.org/articulo.oa?id=13603003

Guardia Rolando, I. (2007). Fuga de venezolanos durante la Revolución Bolivariana (1998-2007). Investigaciones geográficas, (44), 187-198.

Guzmán Ordaz, R. G. (2009). Hacia un análisis interseccional de los procesos migratorios feminizados y la ciudadanía. Investigación y género: avance en las 
distintas áreas del conocimiento: I Congreso Universitario Andaluz: Sevilla, 17 y 18 de junio 2009, 567-590. Universidad de Sevilla.

Halpern, G. (2006). Etnicidad, inmigración y política: representaciones y cultura política de exiliados paraguayos en Argentina. Buenos Aires: Prometeo.

Hernández, M. (2016). "Esto ya no es crisis, es pobreza" Experiencias de descenso social de la clase media Venezolana. Espacio Abierto. Cuaderno Venezolano de Sociología, 25(3), 311-332. Disponible en:<http://www.redalyc.org/articulo.oa?id=12249678022> ISSN 1315-0006

Koechlin, J., Vega, E. y Solórzano, X. (2018). Migración Venezolana al Perú: proyectos migratorios y respuesta del Estado. Koechlin, J. y Eguren Rodríguez, J. (Eds.) (2018), El éxodo venezolano: entre el exilio y la emigración, 47-96. Madrid: Ob-servatorio Iberoamericano sobre Movilidad Humana, Migraciones y Desarrollo.

Linares, M. D. (2016). Trayectorias migratorias e inserción laboral de migrantes recientes en Santa Rosa-Toay (La Pampa, Argentina). Pilquen-Sección Ciencias Sociales, 19(4), 32-46.

Linares, M. D. (2020). Motivaciones de la emigración venezolana reciente hacia Argentina. El caso de Santa Rosa-Toay, La Pampa, Argentina. Revista De Ciencias Sociales, (168), 123-143. https://doi.org/10.15517/rcs.voi168.43975

Magliano, M. J. (2015). Interseccionalidad y migraciones: potencialidades y desafíos. Revista Estudos Feministas, 23(3), 691-712. https://doi.org/10.1590/0104026X2015v23n3p691

Martínez Pizarro, J. y Orrego Rivera, C. (2016). Nuevas tendencias y dinámicas migratorias en América Latina y el Caribe. Serie Población y Desarrollo. CEPAL- ONU- OIM.

Massey, D., Arango, J., Hugo, G., Kouaouci, A., Pellegrino, A., y Taylor, J. (1993). Theories of International Migration: A Review and Appraisal. Population and Development Review, 19(3), 431-466. doi:10.2307/2938462

Mateo, C. y Ledezma, C. M. (2006). Los venezolanos como emigrantes. Estudio exploratorio en España. Revista venezolana de Análisis de Coyuntura. Universidad Central de Venezuela, Caracas, (2), 245-267.

Mezzadra, S. (2005). Derecho a la fuga. Migraciones, ciudadanía y globalización. Buenos Aires: Tinta limón. 
Naciones Unidas, ACNUR (2019). Venezuelan situation. https://data2.unhcr/org/en/situations/vensit

Naciones Unidas, Organización Internacional para las Migraciones (2018). Tendencias migratorias nacionales en américa del sur/ República Bolivariana de Venezuela. https://robuenosaires.iom.int/sites/default/files/Documentos\%20PDFs/SerieT endenciasNacionalesRepBolVenezuela.pdf

Pacecca, M.I. (2019). Venezolanos/as en Argentina.Una aproximación a las cifras Pacecca, M.I. y Liguori, A.G. Venezolanos/as en Argentina: Un panorama dinámico (2014-2018). Buenos Aires: CAREF Comisión Argentina para Refugiados y Migrantes - OIM - ACNUR.

Panadés Inglés, E. (2011). La emigración venezolana rumbo a España; características sociodemográficas e inserción laboral de una migración latinoamericana en tiempos de crisis. Temas de Coyuntura, 63, 39-68.

Pedone, C. (2010). Cadenas y redes migratorias: propuesta metodológica para el análisis diacrónico-temporal de los procesos migratorios. Empiria. Revista de Metodología de Ciencias Sociales, 19, 101-132.

Pedone, C. y Alfaro, Y. (2018). La migración cualificada en América Latina: nuevas perspectivas teóricas-metodológicas y desafíos. Revista Periplos, 2(1), 3-18.

Pedone, C. y Mallimaci, A. (2019). Trayectorias laborales de la población venezolana en la Ciudad Autónoma de Buenos Aires. C. Blouin (Comp.), Después de la llegada. Realidades de la migración venezolana, 129-148. Lima: Thēmis.

Pedone, C., Mallimaci, A., Gutiérrez, J., \& Delmonte, A. (2019). De la estabilidad económica y la regularidad jurídica al ajuste socioeconómico y la precariedad del trabajo: migración venezolana en la Ciudad Autónoma de Buenos Aires. $L$. Gandini, F. Lozano \& V. Prieto (Coords.), Crisis y migración de población venezolana. Entre la desprotección y seguridad jurídica en Latinoamérica, 209-234.

Pereira, A. (2019). El nexo entre migración, seguridad y derechos humanos en la política migratoria de Argentina (1990-2015). Desafíos, (31), 237-309. https://doi.org/10.12804/revistas.urosario.edu.co/desafios/a.6031

Ramella, F. (1995). Por un uso fuerte del concepto de red en los estudios migratorios. Bjerg, M. y Otero, H., Inmigración y redes sociales en la Argentina Moderna. Tandil: CEMLA-IEHS. 
República Argentina, Dirección Nacional de Migraciones, Estadísticas, Radicaciones. Periódos 2011-2015, 2016, $2017 \quad$ y 2018. http://www.migraciones.gov.ar/accesible/indexA.php?estadisticas

República Argentina, Ministerio del Interior, obras públicas y vivienda, CONARE (Comisión Nacional para los Refugiados), Estadísticas 2012-2016. http://www.migraciones.gov.ar/conare/pdf/estadisticas conare.pdf

Requena, J. y Caputo, C. (2016). Pérdida de talento en Venezuela: migración de sus investigadores. Interciencia, 41(7), 444-453.

Revel, J. (2015). Juegos de escalas. Experiencias de microanálisis. San Martín: Universidad Nacional de General San Martín, UNSAM EDITA.

Romero, K., Rondón, S. y R. de Abreu (2016). Soledad en emigrantes venezolanos, Revista Estudiantil URU, 4, 53-70.

Roniger, L. (2010). Exilio político y democracia. América Latina Hoy, 55(o): 143-172. Recuperado de: http://revistas.usal.es/index.php/1130-2887/article/view/7266

Sala, A. G. (2019). Ingenieros venezolanos residentes en la República Argentina. Buenos Aires: Organización Internacional para las Migraciones. http://argentina.iom.int/co/sites/default/files/publicaciones/INGENIEROS.pd $\underline{f}$

Sayad, A. (2010). La doble ausencia. De las ilusiones del emigrado a los padecimientos del inmigrado. Barcelona: Anthropos.

Viveros Vigoya, M. (2016). La interseccionalidad: una aproximación situada a la dominación. Debate Feminista, $\quad$ (52), 1-17. https://doi.org/10.1016/j.df.2016.09.005 